\title{
A SISTEMATIZAÇÃO DE SABERES PARA ENSINAR ARITMÉTICA NA REVISTA DO ENSINO DE MINAS GERAIS (1928-1930)
}

\author{
THE SYSTEMATIZATION OF KNOWLEDGE FOR TEACHING ARITHMETIC IN \\ THE REVISTA DO ENSINO DE MINAS GERAIS (1928-1930)
}

\author{
LA SISTEMATIZACIÓN DE CONOCIMIENTOS PARA ENSEÑANZA DE LA \\ ARITMÉTICA EN LA REVISTA DO ENSINO DE MINAS GERAIS (1928-1930)
}

\author{
Robert Rene Michel Junior* (iD) $(9$ \\ David Antonio da Costa** (D)
}

\section{RESUMO}

Em Minas Gerais, uma das principais reformas educacionais para o Ensino Primário se instituiu em 1927, a Reforma Francisco Campos, tendo como finalidades promover a instrução popular e incorporar as referências da Escola Nova, no estado. Portanto, o objetivo deste trabalho visa analisar, ao longo de um conjunto de artigos, a sistematização de saberes para ensinar aritmética propostos pelos professores em planos de aula para compreensão de transformações e objetivações destes saberes, que possam caracterizar uma provável aritmética alinhada aos Centros de Interesse. Tomamse como fonte histórica os artigos educacionais, resultados das práticas docentes, encontrados na Revista do Ensino (1928-1930), e que possivelmente reverberaram aquela que seria a nova vaga que tentava se estabelecer. O referencial teórico-metodológico respalda-se na História Cultural e nos saberes profissionais. As considerações indicam uma sistematização dos saberes aritméticos dos Centros de Interesse por intermédio dos artigos de aulas-modelo, onde a rubrica "Arithmetica" relaciona-se à resolução de problemas. O "Calculo" e "Numeros" são vinculados ao ensino de contagem de números e objetos.

Palavras-chave: História da Educação Matemática. Escola Nova. Centros de Interesse. Saberes aritméticos.

\begin{abstract}
In Minas Gerais, one of the main educational reforms for Primary Education was instituted in 1927, the Francisco Campos Reform, with the purpose of promoting popular instruction and incorporating the references of New School, in the state. Therefore, the objective of this work aims to analyze, throughout a set of articles, the systematization of knowledge for teaching arithmetic proposed by teachers in class plans to understand the transformations and objectifications of this knowledge that may characterize a probable arithmetic aligned with the Interest Centers. Educational articles, the results of teaching practices, found in the Revista do Ensino (1928-1930), which possibly reverberate this new wave that is trying to establish itself, are taken as a historical source. The theoreticalmethodological framework is supported by Cultural History and professional knowledge. The

\footnotetext{
* Mestre em Educação Matemática pela Universidade Federal de Juiz de Fora (UFJF). Doutorando pelo Programa de Pós-Graduação em Educação Científica e Tecnológica da Universidade Federal de Santa Catarina (PPGECT-UFSC), Florianópolis, Santa Catarina, Brasil. Avenida Sete de Setembro, 386, Aterrado, Volta Redonda, Rio de Janeiro, Brasil, CEP: 27213-160. E-mail: robertrene15@ hotmail.com.

** Doutor em Educação Matemática pela Pontifícia Universidade Católica (PUC/SP). Professor associado no Departamento de Metodologia do Ensino (MEN) do Centro de Ciências da Educação (CED) da Universidade Federal de Santa Catarina (UFSC), Florianópolis, Santa Catarina, Brasil. Rua Douglas Seabra Levier, 163 ap. 208 Bloco B, Trindade, Florianópolis, Santa Catarina, Brasil, CEP 88040-410.E-mail: david.costa@ufsc.br.
} 
considerations indicate a systematization of the arithmetic knowledge of the Interest Centers through the articles of model classes, where the rubric of "Arithmetica" relates to problem solving. The "Calculus" and "Numbers" are linked to the teaching of counting of numbers and objects.

Keywords: History of Mathematics Education. New School. Centers of Interest. Arithmetic knowledge.

\section{RESUMEN}

En Minas Gerais, una de las principales reformas educativas para la Educación Primaria se instituyó en 1927, la Reforma Francisco Campos, con el propósito de promover la instrucción popular e incorporar los referentes de la Escuela Nueva, en el estado. Por tanto, este trabajo tiene como objetivo analizar, a través de un conjunto de artículos, la sistematización de conocimientos para la enseñanza de la aritmética propuesta por los docentes en los planes de clase para comprender las transformaciones y objetivaciones de este conocimiento que puedan caracterizar una probable aritmética alineada con los Centros de Interés. Se toman como fuente histórica los artículos educativos, fruto de las prácticas docentes, encontrados en la Revista do Ensino (1928-1930), que posiblemente reverberen esta nueva vacante pedagógica que está tratando de establecerse. El marco teórico-metodológico se sustenta en la Historia Cultural y en los conocimientos profesionales. Las consideraciones indican una sistematización del conocimiento aritmético de los Centros de Interés a través de los artículos de clases modelo, donde la rúbrica "Aritmética" se relaciona con la resolución de problemas. El "Cálculo" y los "Números" están vinculados a la enseñanza de contar números y objetos.

Palabras clave: Historia de la Educación Matemática. Nueva Escuela. Centros de Interés. Conocimientos aritméticos.

\section{INTRODUÇÃO}

Este artigo, que é um recorte sobre as primeiras análises da tese de doutoramento produzida no Programa de Pós-Graduação em Educação Científica e Tecnológica (PPGECT) da Universidade Federal de Santa Catarina (UFSC), dialoga com o campo de pesquisa da História da educação matemática e a investigação sobre a sistematização dos saberes para ensinar aritmética, apreendidos na Revista do Ensino de Minas Gerais.

Ao tencionar a produção de uma História da Educação que se aproxima ao professor que ensina matemática, o Grupo Associado de Estudos e Pesquisas sobre História da educação matemática do Brasil (GHEMAT-Brasil) lança mão de esforços para a produção dessa historiografia com base no projeto temático em desenvolvimento "Os Experts e a Sistematização da Matemática para a formação de professores dos primeiros anos escolares, 1890-1990".

Contudo, o que resultou na aproximação e interesse nessa temática proposta? De acordo com De Certeau (1982, p. 57) “Toda pesquisa historiográfica se articula com um lugar de produção sócio-econômico, político e cultural", e nesse sentido, o lugar compreende na 
posição social em que o sujeito está, seus conhecimentos adquiridos ao longo de seus estudos, e as instituições que o regem, por exemplo, os grupos científicos de pesquisa; e, aos programas de graduação e pós-graduação onde são realizadas as investigações.

Revisitando o estudo produzido na jornada no Programa de Pós-Graduação em Educação Matemática da Universidade Federal de Juiz de Fora (PPGEM-UFJF), teve-se a oportunidade de investigar saberes da geometria e desenho inclusos na Revista do Ensino de Minas Gerais na década de 1920. Sendo assim, para futuros estudos foi possível perceber a amplitude dos saberes para o ensino de aritmética inseridas no periódico. Atualmente, vinculado ao GHEMAT-SC e ao Programa de Pós-Graduação em Educação Científica e Tecnológica (PPGECT), houve a oportunidade de aprofundamento a esses estudos.

Em suma, a pesquisa de doutoramento em desenvolvimento versa ao projeto temático dos experts em educação e à constituição de saberes profissionais para o ensino de matemática. Este texto toma como fonte privilegiada de pesquisa a Revista do Ensino de Minas Gerais; em particular, os artigos que têm em seu cerne, as produções sobre os Centros de Interesse entre os anos de 1928 e 1930. O recorte temporal escolhido se relaciona ao ano posterior da implementação da reforma educacional para o ensino primário de Francisco Campos (1927), e também, ao período de criação e extinção das seções educacionais da revista "Secção do Centro Pedagógico Decroly", "Nossos Concursos" e "A Voz da Prática" que possuíam um caráter de divulgar novas propostas educacionais, auxiliando a implementação da pedagogia escolanovista no estado.

Para o estudo sobre os Centros de Interesse, foram encontrados alguns trabalhos que tangenciam esta temática. Destacam-se as dissertações de Fonseca (2015), Souza (2017) e Fontes (2018); a tese de Fernandes (2020), e o artigo científico de Valente (2019).

Fonseca (2015), na busca de compreender os distanciamentos e aproximações para o ensino elementar de geometria entre São Paulo e Sergipe, assinala que os programas mínimos dos dois estados, implementados na década de 1930, prescreviam que os conteúdos a serem ensinados pelos professores deveriam estar alinhados ao método de projetos e aos Centros de Interesse. Ainda na década de 1930, Fontes (2018) aponta que a disseminação da Escola Ativa nos Cursos de Aperfeiçoamento em Sergipe assinalava um trabalho específico com o método dos Centros de Interesse.

Souza (2017), ao examinar as revistas pedagógicas paulistas no recorte temporal entre 1890 a 1930, buscou compreender como se configurava o ensino de problemas aritméticos 
nestes documentos. A autora constata cinco tendências, uma delas que articula o ensino dos problemas com o método dos Centros de Decroly.

A tese de Fernandes (2020) é um trabalho que se aproxima deste artigo, a constar das fontes utilizadas, no caso, a Revista do Ensino de Minas Gerais, como também o tema dos Centros de Interesse para o ensino de aritmética. Nesta investigação, a autora observa uma aritmética a ensinar referente aos Centros de Interesse, e elenca os conteúdos neles presentes. Entretanto, tanto Fernandes (2020), quanto os demais trabalhos citados acima, apresentam uma sistematização dos Centros de Interesses oriundos principalmente das orientações de programas educacionais sobre a pedagogia da Escola Nova.

Já o artigo, aqui desenvolvido, investiga uma sistematização de saberes aritméticos a partir da iniciativa dos professores, dos saberes originados das práticas, lidas a partir de suas aulas-modelo. Essa compreensão sobre as produções e concepções dos professores se alinha à de Valente (2019). O autor analisa dois artigos da Revista Educação de São Paulo, escritos pelos professores Renato Jardim, em 1934, e Luiz Gonzaga Fleury, em 1936. Neles, são discutidos, a partir dos posicionamentos dos professores, os obstáculos do ensino aritmético nos Centros de Interesse.

À vista disso, a hipótese deste trabalho é a ocorrência de uma sistematização dos saberes aritméticos elaborados por meio das divulgações de práticas de professores na Revista do Ensino de Minas Gerais, específica para a metodologia dos Centros de Interesse. Consequentemente, a questão de investigação emerge a partir da hipótese dada: quais os saberes sistematizados pelos professores mineiros, presente nos Centros de Interesse?

Portanto, o objetivo do trabalho visa analisar, ao longo de um conjunto de artigos publicados na Revista do Ensino, a sistematização dos saberes para ensinar aritmética proposta pelos professores em planos de aulas-modelo para compreensão de transformações e objetivações destes saberes, que possam caracterizar uma provável aritmética alinhada a essa nova metodologia de ensino referente à vaga pedagógica da Escola Nova.

Sendo assim, o artigo divide-se em quatro momentos. O primeiro deles discute as referências teóricas-metodológicas utilizadas na pesquisa. O segundo tópico trata da historiografia, envolvendo o movimento da Escola Nova e os Centros de Interesse. O terceiro tópico se restringe à apresentação e à análise dos artigos produzidos pelo professorado mineiro, na Revista do Ensino, entre 1928 e 1930. Por fim, algumas considerações são explicitadas a partir da análise das fontes. 


\section{ALICERCES PARA A INVESTIGAÇÃO HISTORIOGRÁFICA}

Utiliza-se como referencial teórico-metodológico a historiografia pautada na História Cultural e na Cultura Escolar; na conceituação dos saberes profissionais para o ensino de aritmética; e nas discussões que possibilitam e viabilizam a utilização das revistas pedagógicas como fontes de pesquisa.

A História Cultural, originada das críticas à história das mentalidades, toma como objeto as práticas socioculturais de uma comunidade, olhando em direção às suas particularidades, minorias, ritos, crenças e individualidades, antes não valorizadas pelo olhar dos historiadores das mentalidades e por seus posicionamentos centrais de investigação (CHARTIER, 2016).

Para Chartier "a História Cultural, tal como entendemos, tem por principal objecto identificar o modo como em diferentes lugares e momentos uma determinada realidade social é construída, pensada, dada a ler" (2002, p. 16-17). Portanto, a História Cultural possibilita novos horizontes aos objetos de pesquisa, considerando os fenômenos e personagens que inicialmente eram avaliados como irrelevantes no cenário social da época.

Investigar historicamente a trajetória de um aluno, professor ou de uma instituição escolar é possível devido ao sentido que se dá a este processo através da História da educação matemática como principal recurso. Utilizou-se de um diálogo da História Cultural ligada a uma cultura específica, no caso, de uma Cultura Escolar. Julia (2001, p. 10) define o termo cultura escolar como “um conjunto de 'normas' que definem conhecimentos a ensinar e condutas a inculcar, e um conjunto de 'práticas' que permitem a transmissão desses conhecimentos e a incorporação desses comportamentos".

Entende-se aqui, que tanto os saberes quanto as normas escolares são produzidos por meio das relações políticas e sociais dos sujeitos que são parte desta cultura diacronicamente. Este pensamento segue a mesma perspectiva que Chervel (1990) defende a partir dos seus estudos sobre a disciplina escolar, considerando-a como componente curricular construído no interior do sistema escolar, contrapondo a ideia que os conteúdos escolares ensinados na escola são apenas transposições didáticas dos saberes produzidos na academia, conteúdos facilitados e diferenciados para a vida prática, savoir-faire, como o autor menciona. Chervel (1990), diante de seu objeto de pesquisa, justifica a importância dessa historiografia própria: 
encerrada na passividade, na escola receptáculo dos sub-produtos culturais da sociedade. Porque são criações espontâneas e originais do sistema escolar é que as disciplinas merecem um interesse todo particular. E porque o sistema escolar é detentor de um poder todo criativo insuficientemente valorizado até aqui é que ele desempenha na sociedade um papel o quão não se percebeu que era duplo: de fato ele forma não somente os indivíduos, mas também uma cultura que vem por sua vez penetrar, moldar, modificar, a cultura da sociedade global (CHERVEL, 1990, p. 184).

Nessa configuração, tomou-se como objetivo de pesquisa analisar, ao longo de um conjunto de artigos na Revista do Ensino de Minas Gerais, a sistematização dos saberes profissionais para ensinar aritmética proposta pelos professores em planos de aula-modelos para compreensão de transformações e objetivações destes saberes, que possam caracterizar uma provável aritmética alinhada aos Centros de Interesse.

Sendo assim, define-se como saberes profissionais aqueles referentes à formação do professor "objeto da profissão" e aqueles vinculados ao ensino, à prática docente "as ferramentas da profissão", instituídos respectivamente por Hofstetter e Schneuwly (2017) como os saberes "a" ensinar e "para" ensinar. Essa caracterização é incorporada aos saberes profissionais do professor que ensina matemática, a partir das matemáticas "a" e "para" ensinar (VALENTE, BERTINI, MORAIS, 2017).

O artigo utiliza como fonte de pesquisa a Revista de Ensino de Minas Gerais, e nele é defendida a utilização de periódicos como fontes de pesquisa que se embasam nos debates do capítulo de livro "Fontes Impressas" de Luca (2008). Há uma aproximação da autora nos argumentos sobre as fontes históricas, segundo as publicações da imprensa no Brasil. Um dos primeiros trabalhos históricos que aborda a dinâmica de utilização de periódicos (jornais e revistas) como fontes principais é a obra "Bravo Matutino" de Helena Capelato e Maria Ligia Prado, publicada em 1980. Nela as autoras explicitam que:

\begin{abstract}
Os estudos históricos no Brasil têm dado pouca importância à imprensa como objeto de investigação, utilizando-se dela apenas como fonte confirmadora de análises apoiadas em outros tipos de documentação [...]. A escolha de um jornal como objeto de estudo justifica-se por entender-se a imprensa fundamentalmente como instrumento de manipulação de interesses e de intervenção na vida social; nega-se, pois, aqui, aquelas perspectivas que a tomam como mero "veículo de informações", transmissor imparcial e neutro dos acontecimentos, nível isolado da realidade político-social na qual se insere (CAPELATO; PRADO, 1980 apud LUCA, 2008, p. 118).
\end{abstract}

Houve, no início do século XX, no Brasil, um crescimento significativo na quantidade de publicações das revistas, e estas eram direcionadas aos diversos grupos sociais. As conhecidas revistas ilustradas ou de variedades tiveram seu estopim de publicações, num 6 
crescimento e força nunca vistos antes. O termo, em especial, variedades é explicado pela autora:

\begin{abstract}
Ainda que grande parte se autodenominasse "de variedades", é possível distinguir a intenção de atingir públicos diversificados. Eram revistas de variedades, mas ao mesmo tempo femininas, masculinas, infantis, esportivas, pedagógicas e educacionais, humorísticas, dedicadas ao rádio, teatro e cinema, étnicas, religiosas, científicas, literárias, voltadas para os interesses do comércio, lavoura ou indústria, sem esquecer o mundo do trabalho, que seguia caminhos próprios, fora do âmbito do mercado (LUCA, 2008, p. 122).
\end{abstract}

Em virtude da possibilidade de utilização de periódicos como fontes históricas, reafirma-se esse abarcamento que busca como fonte de pesquisa a Revista do Ensino de Minas Gerais, com recorte temporal os anos de 1925 a 1932, momento marcado pela pedagogia da Escola Nova. De acordo com o trabalho de Biccas (2008), ao se aprofundar em um panorama histórico sobre a Revista do Ensino, a autora apresenta, em sua análise, dados importantes acerta dos objetivos de sua elaboração, seus conteúdos e sua circulação.

A Revista do Ensino de Minas Gerais foi criada no governo de Afonso Pena em 1892, então presidente de Minas Gerais. Entretanto, nesse primeiro momento, não houve o engajamento necessário das instâncias governamentais para pôr a revista em circulação, e logo foi desativada. Foi apenas no ano de 1925 que o periódico iniciou suas publicações de cunho educacional, suscitando sua ascensão, vinculada à Reforma Fernando Mello Vianna (BICCAS, 2008).

A Revista do Ensino se configura, nessa formatação, como um importante mecanismo para a formação do professorado mineiro, e de produção e circulação de novos saberes e práticas educacionais reconhecidas, para as primeiras décadas do século XX. Justificando-se as potencialidades e possibilidades dos estudos históricos sobre a composição dos saberes profissionais do professor de matemática.

\title{
3 A ESCOLA NOVA E OS CENTROS DE INTERESSE
}

A Escola Nova se concebeu, no final do século XIX, como um movimento educacional internacional como consequência a críticas, inquietudes e oposições às práticas e métodos educacionais do ensino tradicionalista.

John Dewey, filósofo norte-americano, foi um grande influenciador no que se refere a esta vaga pedagógica, proporcionando, assim, novos rumos educacionais em diversos países. 
As hipóteses para seu trabalho empírico surgem através de críticas a duas tendências educacionais norte-americanas conflitantes do final do século XIX.

[...] uma delas tinha como objetivo a preservação do ideal humanista traduzido num currículo que buscava sedimentar elementos da civilização ocidental (representada por William. Torrey Harris) e a outra, que buscava fundamentar o currículo nas novas descobertas científicas sobre a natureza da vida infantil, originárias da psicologia (representada por Granville Stanley Hall) (VALDEMARIN, 2010, p. 30).

Críticas são feitas pelo filósofo em relação à representação curricular de William Harris, que é conteudista, e não leva em consideração o desenvolvimento do aluno em si. Entretanto, a representação voltada às novas descobertas da psicologia de Granville Stanley Hall coloca em evidência o desenvolvimento infantil em detrimento dos saberes curriculares. A partir dessas concepções, "Dewey reconfigura os termos do debate em curso, entendendo que o currículo e a criança devem ser conciliados e harmonizados sem predominância de um dos pólos" (VALDEMARIN, 2010, p. 31).

Dewey estabelece, em 1986, a criação de uma escola-laboratório, vinculada à Universidade de Chicago, a fim de pôr em prática suas hipóteses teóricas. Com isto, ele tem como objetivo experienciar suas ideias, e é através da sua atividade na Escola de Chicago, que não somente aplica suas hipóteses educacionais, mas também produz documentos com suas reflexões. Entre seus trabalhos, algumas palestras foram desenvolvidas nos primeiros anos de funcionamento da escola (VALDEMARIN, 2010).

Entretanto, não foi apenas nos Estados Unidos que tais pesquisas estavam em desenvolvimento. Na Europa, nomes como Maria Montessori e Jean-Ovide Decroly se debruçavam nas possibilidades de inclusão e disseminação dos ideais da Escola Nova, nos currículos e também nas práticas pedagógicas.

Na perspectiva de Decroly, as dificuldades de aprendizagem ganharam atenção em seus estudos sobre o pensamento humano. De forma semelhante a Dewey, são criadas escolas laboratórios, como o Instituto de Educação Especial e L'Ermitage, a fim de investigar suas hipóteses. A organização curricular por meio dos Centros de Interesse foi uma das marcas deixadas por Decroly (VALDEMARIN, 2010).

Os centros de interesse atendiam, segundo as proposições de Decroly, às motivações do aluno e forneciam resposta para suas inquietações; simultaneamente, atendiam às exigências do trabalho intelectual, pois, valendo-se da observação, da associação das ideias concretas e abstratas no tempo e no espaço, organizavam as informações em conjuntos ordenados de conhecimentos. O princípio da globalização - presente nas atividades cotidianas - explica que o mundo é apreendido pelos indivíduos como 
totalidade, sem reduzi-lo a divisões arbitrárias e artificiais como aquelas presentes nos programas escolares. (VALDEMARIN, 2010, p. 93).

Portanto, as ideias escolanovistas, junto com o método dos Centros de Interesse chegam ao Brasil, entre as décadas de 1920 e 1930. A pedagogia traz novas atuações educacionais, onde se observava uma perspectiva diferente nas relações entre professoraluno, pela qual esse aluno passaria a ser o foco da aprendizagem com o auxílio docente. A escola, nesta concepção, deveria se moldar ao estudante e a aprendizagem se desenvolveria por meio de experiências, atividades, por seus interesses, e de forma colaborativa (VALENTE, PINHEIRO, 2017).

Em Minas Gerais, sob a justificativa de modernização e transformação da realidade social mediante a instrução popular, Antônio Carlos, presidente do Estado de Minas, com apoio de seu Secretário do Interior, Francisco Campos, propõe uma reforma educacional no ensino primário integrando a pedagogia da Escola Nova ao alcance de tais finalidades (CARVALHO, 2012).

A Reforma Francisco Campos (1927-1928) se apoiou ainda em estudos da Biologia, levando em consideração o aluno como um "ser em crescimento", e da Psicologia, através das bases comportamentais e da experimentação; configurou mudanças no currículo e nas práticas pedagógicas ao buscar, principalmente, a aproximação do diálogo entre a escola e a sociedade. (CARVALHO, 2012).

A proposta escolanovista introduziu uma renovação no ensino em que conhecimento do desenvolvimento psicológico ampliou os saberes pedagógico-didáticos pródesenvolvimento integral da criança e transformou a escola ao considerar os interesses e as necessidades do educando, dando àquela um caráter dinâmico e vivo, de trabalho, de respeito e de participação; diferentemente do didatismo tradicional (CARVALHO, 2012, p. 191).

De acordo com o programa do ensino primário aprovado por Francisco Campos, a disciplina Lições de Coisas é criada para o ensino desses Centros. Há ainda sugestões para tal estruturação por meio de três bases teóricas, ou mesmo "três operações intellectivas": a observação, associação de ideias e expressão. Cada um desses eixos tinha sua importância. A observação era o ponto de partida do método. É o momento em que a curiosidade sobre um assunto se manifesta. A associação é a generalização das informações recebidas, junto à comparação com aqueles fatos já assimilados. Por último, a expressão exterioriza o que se aprendeu, o que permanece no intelecto. O programa ainda ilustra uma série de sumários 
esquemáticos com as orientações sobre a observação, associação e expressão, pertencentes ao método, para os quatro anos do ensino primário (MINAS GERAIS, 1928).

Assim sendo, os Centros de Interesse são incorporados às legislações de Minas Gerais, contudo, não se tinha um parâmetro específico de como colocar essas diretivas em prática. Logo, a seguir, discorre-se sobre as tentativas de instituir tal método nas aulas-modelo executadas por professores, validadas pela Instrução Pública, e veiculadas pelas Revista do Ensino de Minas Gerais.

\section{OS CENTROS DE INTERESSE NA REVISTA DO ENSINO}

Retomando o objetivo do artigo, que visa analisar a sistematização dos saberes para ensinar aritmética proposta pelos professores em planos de aula modelos presentes nos artigos da Revista do Ensino, a partir dos Centros de Interesse, identifica-se, primeiramente, o quantitativo de artigos que fazem alusão a essa metodologia de ensino.

Dentre os anos de 1928 e 1930, constatam-se 40 referências aos Centros de Interesse. Relacionados aos artigos que abordam de alguma forma os Centros de Interesse, destacam-se dois recortes: a) artigos que possuem um lugar privilegiado na revista, aqueles que detêm certa independência, ligados às discussões sobre a abordagem teórica e metodológica de Decroly na "Secção do Centro Pedagógico de Decroly"; b) artigos que são resultados de divulgações de práticas pedagógicas bem-sucedidas, reconhecidas pela Instrução Pública de Minas Gerais, pertencentes à seção "Nossos Concursos" e "A voz da prática".

\subsection{Secção do Centro Pedagógico Decroly}

A “Secção do Centro Pedagógico Decroly” foi instituída na Revista, no ano de 1928, logo após a Reforma Francisco Campos para o ensino primário, com o objetivo de orientar as novas práticas educacionais que deveriam ser incorporadas em Minas Gerais. De um lado, a Reforma explicitava como deveria se moldar a "Nova Escola", no estado, porém, os professores não tinham as orientações de como ensinar. Os únicos métodos que se conheciam eram aqueles já institucionalizados ao longo de anos de práticas, e vinculados ao ensino tradicional e até mesmo pela vaga do Método Intuitivo. A criação desta seção foi um dos muitos esforços para estabelecer a nova concepção pedagógica originária nos Estados Unidos e na Europa. 
Nesse sentido, foi criada a importante 'Seção do Centro Pedagógico Decroly', com o objetivo de orientar os professores com pouca e nenhuma experiência com este referencial teórico e metodológico. Esta seção foi publicada somente nos dois primeiros anos de implantação da reforma (1928 e 1929), momento chave para que os professores pudessem conhecer o que estava se desenvolvendo em outros estados e países que adotaram este referencial. Destacamos ainda que a característica dessa seção foi publicar conferências, trabalhos, experiências que abordavam essa temática, foram inúmeros os artigos que enfatizaram como trabalhar com: 'Centros de Interesse; modelos de aula e de lição; indicação de bibliografia específica para professores' (RODRIGUES, BICCAS, 2015, p. 158).

A partir dessas justificativas, analisaram-se os artigos que continham o método dos Centros de Interesse em seus textos.

\begin{tabular}{|c|c|c|}
\hline Título & Autoria & Ano \\
\hline Secção do Centro Pedagógico Decroly - O Systema Decroly & $\begin{array}{c}\text { Julio de } \\
\text { Oliveira }\end{array}$ & 1928 \\
\hline $\begin{array}{c}\text { Secção do Centro Pedagógico Decroly: Centro de interesse: a alimentação - Assunto do } \\
\text { dia: o leite }\end{array}$ & $\begin{array}{c}\text { Maria da } \\
\text { Gloria Barros }\end{array}$ & 1928 \\
\hline $\begin{array}{c}\text { Secção do Centro Pedagógico Decroly: Do Caderno de Preparações das Lições para o } \\
\text { ensino Primário: Centro de interesse: a alimentação - Assunto da semana: a laranja }\end{array}$ & $\begin{array}{c}\text { Maria da } \\
\text { Gloria Barros }\end{array}$ & 1928 \\
\hline Secção do Centro Pedagógico Decroly: Um programa de escola infantil & $\begin{array}{c}\text { Julio de } \\
\text { Oliveira }\end{array}$ & 1928 \\
\hline $\begin{array}{c}\text { Secção do Centro Pedagógico Decroly - Do Caderno de Preparações das Lições do 1 } \\
\text { Anno. Centro de Interesse: os meios de transporte. Assumpto da semana: o automóvel. }\end{array}$ & $\begin{array}{c}\text { Maria da } \\
\text { Gloria Barros }\end{array}$ & 1929 \\
\hline $\begin{array}{c}\text { Secção do Centro Pedagógico de Decroly: Centro de Interesse: alimentação. Assunto: o } \\
\text { abacate }\end{array}$ & $\begin{array}{c}\text { Maria da } \\
\text { Gloria Barros }\end{array}$ & 1929 \\
\hline $\begin{array}{c}\text { Secção do Centro Pedagógico de Decroly: Centro de Interesse: necessidade de luctar } \\
\text { contra a intemperies }\end{array}$ & $\begin{array}{c}\text { Maria da } \\
\text { Gloria Barros }\end{array}$ & 1929 \\
\hline
\end{tabular}

Quadro 1 - Secção do Centro Pedagógico Decroly e os Centros de Interesse Fonte: Os autores (2021)

Nessa composição, o primeiro artigo encontrado e analisado da "Secção do Centro Pedagógico Decroly”, se intitula "O Systema Decroly”, e foi escrito por Julio de Oliveira, no volume 4, número 26, de 1928, da Revista do Ensino.

O artigo é o relato da realização de uma conferência no Grupo Escolar Barão do Rio Branco, na capital mineira, Belo Horizonte, para um grande número de professores e autoridades relacionadas ao ensino. A palestra tinha tanto um caráter informativo, quanto formativo, a fim de trazer a concepção pedagógica dos Centros de Interesse para os professores. Infere-se, a partir da leitura do artigo, que Julio de Oliveira foi enviado em missão pedagógica para Bruxelas para visitar e recolher dados sobre as escolas primárias, participando de cursos de formação na escola de Érmitage, com o próprio Jean-Ovide 
Decroly. Partindo desse princípio, Julio de Oliveira (1928a) afirma que suas considerações, explanadas na palestra, se originaram de interpretações oriundas da teoria de Decroly.

\begin{abstract}
Passei a encaral-o respeitosamente, percebendo no referido systema um corpo lógico, com base legitima na psychologia da creança. Em vez de consideral-o como um methodo simplesmente, tomo-o como um corpo pedagógico completo. Sendo assim, divido-o em partes, a saber: o conhecimento biológico e psychologico da creança, colocando esta como centro do systema; os centros de interesse: o methodo propriamente dito. Estas duas partes ultimas derivam da primeira (OLIVEIRA, 1928a, p. 95).
\end{abstract}

Essa passagem aponta que os estudos de Biologia e Psicologia provenientes do movimento escolanovista estão diretamente ligados aos Centros de Interesse, entendendo como um sistema de ensino completo. De acordo com Julio de Oliveira (1928a), o interesse estaria conectado às necessidades biológicas para a vida do aluno, com debates sobre "alimentação, defesa, trabalho e recreação".

A justificativa para implementação desse método, era o de unificação dos conhecimentos ensinados. Tomando como exemplo a alimentação, far-se-ia necessário discussões sobre um tema central em todas as áreas do ensino, respeitando suas limitações. Uma das dificuldades elencadas pelo ensino já instituído é o caráter desconexo entre os temas explorados pelas disciplinas, e, portanto, o Método Decroly serviria como uma possibilidade de diálogo entre as disciplinas.

\footnotetext{
O centro de interesse póde ser comparado á estrella dos navegantes do ensino, para evitar que a actividade mental se perca no emaranhado das licções desconnexas.

Estas licções desconnexas é o que temos constatado entre as varias disciplinas dos programmas. Unificar todas essas partes, é dar-lhes corpo e vida no domínio intellectual. (OLIVEIRA, 1928a, p. 95-96).
}

De acordo com autor do artigo, o método é composto com duas vertentes dialógicas: a aquisição e a expressão. A primeira é realizada através da observação dos alunos, interação por meio dos sentidos, comparação de objetos, fatos e ideias, que tem por finalidade gerar o interesse, a curiosidade e as impressões iniciais sobre o tema.

A partir da aquisição, o próximo passo vem ser a exteriorização desses conhecimentos pelos diferentes tipos de expressões. Oliveira (1928a) aborda em sua palestra formas de expressão, sendo elas: a elocução, o desenho, a escrita e a leitura, os trabalhos manuais, e os jogos educativos. Por fim, o professor apresenta um plano de aula-modelo denominado "Centros de Interesse: a creança e a escola" e subtítulo "assumpto do dia: o conhecimento da 
escola”. Identificam-se, orientações sobre observação, associação e realização do método. Em seguida, é anunciado o tópico "Exercícios", exemplificando como se dariam os trabalhos com as diferentes disciplinas. Constatam-se nesse plano Escripta, Orthographia, Modelagem, Exercicio e Canto e Números. Nesta última, percebem-se as orientações de contagem dos números de 1 a 10, e decomposição por meio da adição.

Oliveira (1928b) ainda escreve outra orientação, no número 28 da revista, do mesmo ano. Agora, são ostentados treze modelos de aulas no formato dos Centros de Interesse: 1) A boneca e os collegas: escala e ideia de menor e maior; 2) A casa da boneca: contagem; 3) O vestuario da boneca: contagem; 4) O gatinho: contagem; 5) A galinha e os pintinhos: (como nos planos precedentes); 6) Os soldadinhos; 7) O quartel; 8) Instrumentos militares; 9) A Bandeira; 10) Os canteiros e as plantas; 11) O repuxo e o tanque; 12) Os peixinhos e os patinhos; 13) Os patinhos. Em todos, a aritmética aparece com a rubrica "Numeros" e o conteúdo estudado se vinculava, em suma, na contagem de elementos do cotidiano, alinhados ao centro especificado. Por exemplo, no Centro de Interesse "Os soldadinhos" orientava-se contar as figuras dos soldados. Já no centro "O quartel”, o cálculo do número de portas e janelas deveria ser realizada.

A julgar por essas primeiras orientações, respaldadas teoricamente pelos ensinamentos de Decroly e apropriadas pelo professor Julio de Oliveira, outras propostas começam a ganhar forma dentro do periódico. Maria da Glória Barros, professora do grupo escolar Pedro II, é um nome que ganha visibilidade nessa seção, com cinco artigos. Suas três primeiras aulasmodelo, publicadas nos números 26, 27 do ano de 1928 e no número 33 em 1929, da Revista, apresentam o Centro de Interesse em comum, a alimentação, variando apenas seus assuntos, sendo eles respectivamente: o leite; a laranja; o abacate.

A aritmética, ali presente, se inscrevia como "Calculo" no caso dos Centros de Interesse "o leite" e "o abacate", e "Calculo occacional mecânico" relativo ao Centro de Interesse "a laranja". São abordados como possibilidades educacionais, exercícios de contagem, como os trabalhos de Oliveira (1928b), além do estudo de unidade e dezena, utilização de jogos educativos, e resolução de problemas com base na adição e subtração, e no cálculo mental (BARROS, 1928a; 1928b; 1929a).

Os demais artigos de Barros (1929b; 1929c) tinham como Centro de Interesse "necessidade de luctar contra a intemperies" e "os meios de transporte: assumpto da semana: o automóvel". A aritmética, nesses dois momentos, aparecia mais uma vez com a assinatura de "Calculo occacional mecânico". Percebe-se a possibilidade de trabalho com a contagem de 
números e objetos, escrita de números, decomposição numérica, além de problemas a partir de preço de compra e venda da gasolina para o artigo com a temática do automóvel.

Portanto, vê-se uma predominância da aritmética, nessas instâncias oficiais, aparecendo no formato de "Números" e "Calculo". Sobre o que se deveria ensinar, há uma prevalência para o ensino da contagem, embora apareçam outras orientações, como a resolução de problemas oriundas das propostas de Barros.

\title{
4.2 Os Nossos Concursos
}

Caminhando para o próximo tópico, debruçam-se os olhares para a seção "Nossos Concursos". Os concursos promovidos pela Revista do Ensino eram um espaço a fim de reconhecer como o professorado mineiro estava articulando suas aulas com as inovações do ensino escolanovista da época, e a incentivá-los mediante premiações. As inscrições nos concursos eram realizadas pelos próprios professores. Em consequência, os melhores trabalhos eram premiados, e expostos na revista para incitar tanto a participação de outros professores, como também inspirar demais práticas docentes. Com isso, há uma maior veiculação de saberes incitados pelos esforços de criação e utilização dessas aulas nas práticas educacionais dos professores mineiros. Chervel (1990), nessa perspectiva, defende a importância da prática docente na constituição dos saberes, produzidos no seio da escola, a partir da criatividade e das possibilidades de criação por seus estudos e práticas.

De acordo com Rodrigues e Biccas (2015):

\begin{abstract}
Era proposta dos 'concursos' que os professores e diretores primários escrevessem sobre os temas e assuntos ligados ao ensino, estudando-os e discutindo-os, alguns deveriam ser teoricamente analisados e outros deveriam aliar teoria e prática nas sugestões de atividades. Os 'concursos' tiveram dois tipos de estrutura. Nos dois primeiros meses em que foram editados constavam de dois tópicos, o primeiro com perguntas voltadas a uma abordagem teórica sobre o tema e o segundo com uma abordagem voltada às práticas de sala de aula. A segunda estrutura foi a que de fato predominou. Constava de três tópicos, o primeiro e segundo traziam perguntas para elaboração de argumentação e o terceiro voltado à descrição de aulas modelo sobre qualquer ponto das disciplinas do programa de ensino primário (RODRIGUES, BICCAS, 2015, p. 159).
\end{abstract}

Verifica-se (quadro 2) que os Centros de Interesse ganham destaque na seção "Nossos Concursos" com 16 proposituras executadas por professores, nas quais sua maioria foi estabelecida no ano de 1929. 


\begin{tabular}{|c|c|c|}
\hline Título & Autoria & Ano \\
\hline Os nossos concursos: Centro de Interesse: O café & Zilda Gama & 1929 \\
\hline Os nossos concursos: Centro de Interesse: A água & $\begin{array}{c}\text { Philocelina da Costa } \\
\text { Almeida }\end{array}$ & 1929 \\
\hline Os nossos concursos: Centro de Interesse: A Laranja & Laura Magalhães & 1929 \\
\hline Os nossos concursos: Centro de Interesse: a árvore & Maria Horta & 1929 \\
\hline Os nossos concursos: Centro de Interesse: O chocolate & Maria Queiroga & 1929 \\
\hline Os nossos concursos: Centro de Interesse: a água & Sergio Ferreira & 1929 \\
\hline Os nossos concursos: Centro de Interesse - Criação de aves domésticas. & Fausto Gonzaga & 1929 \\
\hline Assunto: o galo & Marieta de Araújo & 1929 \\
\hline Os nossos concursos: Centro de Interesse: o continente sul americano & Silva & 1929 \\
\hline escola & Aracy Noronha & 1929 \\
\hline Os nossos concursos: Centro de Interesse: Assimilação Chlorophylliana & Cifra Lacerda & 1929 \\
\hline Os nossos concursos: Centro de Interesse: o sal & Djanira Pacheco & 1929 \\
\hline Os nossos concursos: Centro de Interesse: o bico da seda & Uma professora & 1929 \\
\hline Os nossos concursos: Centro de Interesse: O valle do Amazonas & Silvia Nunes & 1929 \\
\hline Os nossos concursos: Centro de Interesse: A bandeira & Maria do Céo Gomes & 1929 \\
\hline Os nossos concursos: Centro de Interesse: A alimentação: o leite e o ovo & Sylveria da Costa & 1930 \\
\hline
\end{tabular}

Quadro 2 - Nossos Concursos e os Centros de Interesse

Fonte: Os autores (2021)

Para os concursos, as rubricas para o ensino da aritmética presente nos Centros de Interesse não possuíam uma uniformidade, entretanto, oito dessas aulas vinham com tal nomenclatura. Configuram-se com o termo de conteúdo "arithmetica" os artigos dos professores: Zilda Gama, Maria Noronha Horta, Maria da Conceição Queiroga, Fausto Gonzaga, Marieta de Araújo, Aracy Noronha, Djanira Magalhães Pacheco, e um último que não se tem a autoria revelada e é assinado como "Uma Professora".

As propostas desses professores se instituem, quase que totalmente, em uma aritmética voltada para a resolução de problemas ${ }^{1}$. Toma-se como exemplo o "Centro de Interesse: O café" de Zilda Gama, onde a aritmética é trabalhada a partir da resolução de problemas envolvendo o plantio, a compra e venda do café, junto aos conteúdos de adição e subtração de números inteiros.

\footnotetext{
${ }^{1}$ Verifica-se nos artigos "Centro de Interesse: O chocolate" de Maria da Conceição Queiroga e no "Centro de Interesse: o continente sul americano" de Marieta de Araújo, não apenas a indicação de resolução de problemas para a rubrica "Arithmetica", mas também, a contagem de bombons para o primeiro artigo aqui citado, e o estudo de ordenação de números, no segundo.
} 


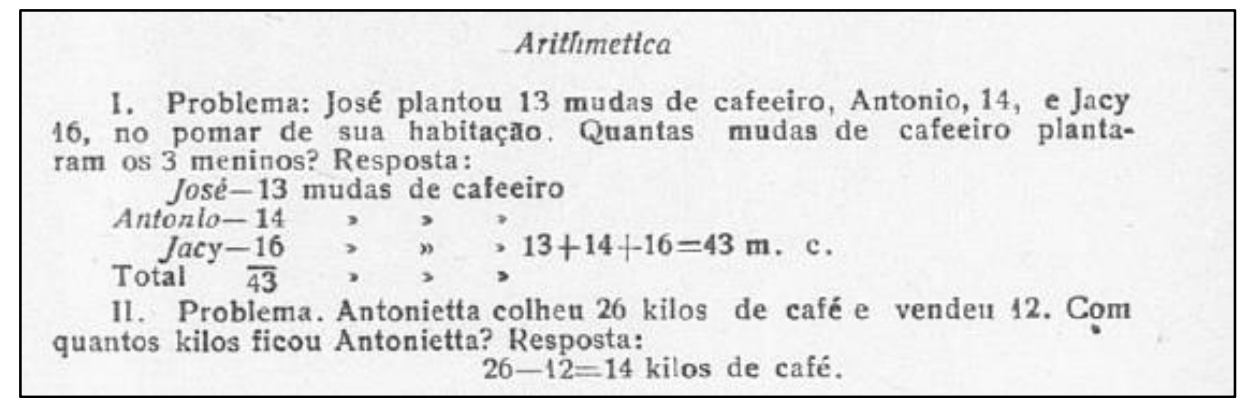

Figura 1 - Centro de Interesse: O café

Fonte: Revista do Ensino, v. 4, no 30. p. 64-67, 1929.

Dentre esses oito artigos, três possuem uma particularidade. Diretamente ligada à lição de "Arithmética", sucede-se uma rubrica específica denominada "Problemas". É o caso do “Centro de Interesse: o sal” de Djanira Magalhães Pacheco e o "Centro de Interesse: o bico da seda" subscrito por "Uma Professora". Em particular, o artigo de Djanira Magalhães Pacheco permeava o estudo de dados estatísticos para a aritmética, e a resolução de problemas por divisão e multiplicação junto ao tema da atividade.

Arithmetica-Segundo dados estatisticos recentemente
publicados, a safra de sal do Rio Grande do Norte, no pre-
sente anno, começará em Set mbro. Existem em stock nas
salinas 325.000 toneladas da safra do anno passado, cuja produ-
cęão foi e 544.133 .583 kilos, dos quaes foram exportados,
de janeiro a dezembro, 219.133 .882 kilos, produzindo para a
União uma renda de 4.382 contos de imposto de consumo.
Problema- Um saquinho de sal contém 2 kilos de sal
e é vendido por $1 \$ 000$. Quanto custará uma tonelada?

Figura 2 - Centro de Interesse: $\mathrm{O}$ sal

Fonte: Revista do Ensino, v. 4, nº 37. p. 53-55, 1929.

Ainda, em relação aos artigos publicados em "Nossos Concursos", a aritmética aparece com a designação "Calculo" e "Calculo occacional mecânico" nas produções de Maria do Céo Gomes ${ }^{2}$, e Sylveria Homem da Costa $^{3}$. A contagem de números naturais ganha prioridade nesses trabalhos, como a contagem da quantidade de cores e estrelas da bandeira do Brasil, por exemplo.

Um único artigo intitulado "Centro de Interesse: a água” de Sérgio Ferreira difere dos demais centros, apresenta a aritmética pela rubrica de "Frações ordinárias", abordando o estudo de frações, das nomenclaturas de seus elementos como numerador e denominador (identificação dos mesmos nas frações), e a leitura das frações, como um meio, um terço, um

\footnotetext{
${ }^{2}$ Centro de Interesse: A bandeira. Revista do Ensino, v. 4, n 40. p. 60-63, 1929.

${ }^{3}$ Centro de Interesse: A alimentação: o leite e o ovo. Revista do Ensino, v. 5, no 47. p. 73-75, 1930.
} 
quarto, e assim sucessivamente. A assinatura "Problema" aparece no corpo da revista de forma similar ao trabalho de Djanira Magalhães Pacheco, e traz como estudo, problemas relacionados ao reservatório de água.

Por fim, vale ressaltar que não havia uma obrigatoriedade de alcance a todas as matérias estudadas no ensino primário, e como consequência, constatam-se três ${ }^{4}$ artigos sem mencionar saberes aritméticos.

Verifica-se que os trabalhos tratam em seus conteúdos uma aritmética para ensinar envolvendo a resolução de problemas, principalmente para o recorte "Arithmetica"e a contagem de números naturais para o "Calculo" e "Calculo occacional mecânico".

\subsection{A Voz da Prática}

A Voz da Prática se torna, a partir de 1930, uma nova vertente dos Nossos Concursos, retomando artigos já premiados e, além disso, publicando novas aulas-modelo. Estes, mesmo não ganhando algum tipo de premiação, são julgados como relevantes pela Diretoria de Instrução Pública para serem divulgados pela revista, em Minas Gerais.

[...] A Voz da Prática abriu um espaço para a publicação dos bons trabalhos enviados para a seção Nossos Concursos e que não foram por eles premiados. $\mathrm{O}$ compromisso da redação era publicar, até então, apenas os trabalhos dos vencedores. 'A Voz da Prática' abriu ainda um espaço para os trabalhos dos professores das escolas normais e assistentes técnicos que não puderam participar dos 'concursos', já que um dos critérios definidos por seus promotores restringia, quanto ao público alvo, os professores primários. Alguns autores que contribuíram com 'A Voz da Prática' foram os seguintes: Firmino Costa, Diretor da Escola de Aplicação; Nair Starling, Oscar Arthur Guimarães e Ramos Cesar, assistentes técnicos da instrução (RODRIGUES, BICCAS, 2015, p. 158-159).

O quadro 3 mostra os artigos e os Centros de Interesse que integram a seção "A Voz da Prática".

\begin{tabular}{|c|c|c|}
\hline Título & Autoria & Ano \\
\hline A Voz da Prática: Pesca & Anna de Carvalho & 1930 \\
\hline A Voz da Pratica: Plano de Lição - Centro de Interesse: o feijão & $\begin{array}{c}\text { Delmira de Medeiros } \\
\text { Seixas }\end{array}$ & 1930 \\
\hline A Voz da Pratica: Plano de Lição - Centro de Interesse: o bicho da seda & Noemi Andres & 1930 \\
\hline A Voz da Pratica: Lição modelo - Centro de Interesse: a bandeira & Maria do Céo Gomes & 1930 \\
\hline
\end{tabular}

4 Os trabalhos são: "O Centro de Interesse: A água” de Philocelina da Costa Mattos Almeida; "Centro de Interesse: A Laranja" de Laura Magalhães; e "Centro de Interesse: O valle do Amazonas" de Silvia Nunes. 


\begin{tabular}{|c|c|c|}
\hline A Voz da Pratica: Plano de Lição - Centro de Interesse: os chapéos & Iria Pinto & 1930 \\
\hline A Voz da Pratica: Plano de Lição: Centro de Interesse: O movimento dos \\
seres vivos. & Romeu Venturelli & 1930 \\
\hline A Voz da Pratica: Plano de Lição: Centro de Interesse: A vacca. & Affonsina Palleta & 1930 \\
\hline A Voz da Pratica: Plano de Lição: Centro de Interesse: O trigo. & Maria José Vieira & 1930 \\
\hline A Voz da Pratica: Plano de Lição: Centro de Interesse: O porco. & Clelia Lopes Marques & 1930 \\
\hline A Voz da Pratica: Lições modelo: Centro de Interesse: A abelha & Helena Rocha & 1930 \\
\hline A Voz da Pratica: Lições modelo: Centro de Interesse: O carneiro & Cornelia Goulart & 1930 \\
\hline A Voz da Pratica: Lições modelo: Centro de Interesse: A galinha & Irene Lustosa & 1930 \\
\hline A Voz da Pratica: Plano de Lição: Centro de Interesse: a árvore. & Maria José Paletta & 1930 \\
\hline A Voz da Pratica: Plano de Lição: Centro de Interesse: O arco-iris. & Jayra de Queiros \\
Teixeira & 1930 \\
\hline A Voz da Pratica: Plano de Lição: Centro de Interesse: A casa & Maria de Castro Chagas & 1930 \\
\hline A Voz da Pratica: Plano de Lição: Centro de Interesse: alimentação de & Elmaia Ferreira da & 1930 \\
origem animal: carnes, lacticinios, ovos. & cunha & 1930 \\
\hline A Voz da Pratica: Plano de Lição: Centro de Interesse: a lenha, o \\
aquecimento, assumpto incidental & $\begin{array}{c}\text { Maria da Gloria Ferreira } \\
\text { da silva }\end{array}$ & \begin{tabular}{c}
1930 \\
\hline
\end{tabular}
\end{tabular}

Quadro 3 - A Voz da Pratica e os Centros de Interesse

Fonte: Os autores (2021)

A composição e disposição dos artigos são muito semelhantes àquelas vistas anteriormente nos "Nossos Concursos". Dos 17 artigos mencionados acima, a aritmética é subscrita em três tópicos de ensino: "Numeros", "Calculo" e "Arithmetica".

A análise das fontes indica que três dos dezessete artigos contêm a subscrição "Arithmetica". Para o primeiro deles encontrado, "Centro de Interesse: A Pesca", de Anna de Carvalho Britto, o trato com a aritmética é evidenciado pela resolução de problemas, considerando as quatro operações fundamentais. De forma semelhante, o "Centro de Interesse: os chapéos", de Iria Pinto, e o "Centro de Interesse: alimentação de origem animal: carnes, lacticinios, ovos", escrito por Elmaia Ferreira da Cunha, também prescrevem o uso dos problemas para ensinar aritmética.

Já as rubricas "Numeros", "Calculo", indicam, no geral, o ensino de contagem de números naturais. A título de exemplo, toma-se o "Centro de Interesse: o feijão", produzido por Delmira de Medeiros Seixas, pertencente ao número 42, da Revista do Ensino, onde a professora propõe para cada aluno "Fazer contar vagens fechadas e os grãos contidos, em uma, duas, três, ou mais, conforme o andamento da classe" (SEIXAS, 1930, p. 55).

Nesse recorte, há apenas uma exceção. O trabalho de Clelia Lopes Marques em "Centro de Interesse: O porco", que mesmo apresentando um ensino de "Calculo", além das contagens de objetos que representariam os animais, indica o ensino por meio do uso de 
problemas: "Com porquinhos cortados em cartolina, fazer problemas de somma e subtracção ao alcance das creanças; e também contar até certo numero” (MARQUES, 1930, p. 56).

Há, ainda, dois artigos que trazem em si, saberes pertinentes à aritmética, mas não se inscrevem em uma "Arithmetica", "Calculo" ou "Numeros". No caso, há a ausência de uma especificação. "Centro de Interesse: O arco-iris" de autoria de Jayra de Queiros Teixeira, que inclui mais uma vez o ensino de aritmética por meio de contagem de números, e "Centro de Interesse: a lenha, o aquecimento, assumpto incidental" escrito de Maria da Gloria Ferreira da Silva, onde se propõe o ensino de cálculo voltado nas quantidades de lenha e seus preços, apontando para um estudo ligado à resolução de problemas aritméticos.

Finalmente, encontram-se três artigos que falam sobre os Centros de Interesse na seção “A Voz da Prática”, mas não apresentam saberes aritméticos, correspondendo assim aos artigos produzidos por Romeu Venturelli, Maria José Paletta, e Maria de Castro Chagas.

Os saberes sistematizados por essa gama de professores, indicam uma aritmética dos centros de interesse voltada para o ensino de contagem de números naturais para as rubricas de "Calculo" e "Numeros", e resolução de problemas especificamente para "Arithmetica".

\section{CONSIDERAÇÕES FINAIS}

O movimento da Escola Nova, em Minas Gerais, como se observou, ganhou força entre as décadas de 1920 e 1930. Um dos esforços iniciais para essa inclusão de novas pesquisas que aconteciam, promoveu a movimentação não só das instâncias políticas, mas também dos professores que, munidos de sua vontade e criatividade, alçaram esforços para viabilizar novos métodos de ensino vinculados às novas questões de aprendizagem, inerente ao interesse e bem-estar do aluno.

Pertinente ao estudo da História da educação matemática, quais os saberes sistematizados pelos professores mineiros, para o ensino da aritmética presente nos Centros de Interesse?

A análise dos artigos de aulas-modelo confeccionadas pelos professores nos segmentos "Secção do Centro Pedagógica Decroly", "Nossos Concursos" e "A voz da Prática" propiciou um entendimento sobre uma aritmética ali proposta. Nessa configuração, percebe-se a prevalência de atividades que evidenciam uma institucionalização do ensino de contagem e dos problemas utilizados para ensinar aritmética, nos Centros de Interesse. 
Destaca-se que as rubricas as quais fazem referências à aritmética, também possuem particularidades. Na medida em que os autores das obras apresentam "Arithmetica", "Numeros", "Calculo" e "Calculo occacional mecânico", um tipo de saber vai se configurando. Uma "Arithmetica" orientada ao trabalho com os problemas aritméticos se sobressai. Em menor intensidade, a contagem de números e objetos são abordagens que também ganham notoriedade.

Com isso, identifica-se um processo de objetivação de saberes, partindo do empenho, da criatividade e das atividades dos professores junto à sua prática, para uma aritmética contida nos Centros de Interesse, especialmente na utilização de problemas, no princípio da contagem para estudo dos números naturais.

Para a continuação dos estudos, intenciona-se, como possibilidade, investigar a sistematização de saberes aritméticos por via dos agentes da educação, divulgadas em lugares diversos na Revista do Ensino de Minas Gerais.

\section{REFERÊNCIAS}

BARROS, M. G. Secção do Centro Pedagógico Decroly. Centro de interesse: a alimentação Assunto do dia: o leite. Revista do Ensino. Belo Horizonte, v. 4, no 26. p. 106-108, out., 1928a.

BARROS, M. G. Secção do Centro Pedagógico Decroly. Centro de interesse: a alimentação Assunto da semana: a laranja. Revista do Ensino. Belo Horizonte, v. 4, no 27. p. 88-91, nov., $1928 b$.

BARROS, M. G. Do Caderno de Preparações das Lições do $1^{\circ}$ anno. Centro de Interesse: os meios de transporte. Assumpto da semana: o automóvel. Revista do Ensino. Belo Horizonte, v. 4, no 31. p. 76-81, mar., 1929a.

BARROS, M. G. Secção do Centro Pedagógico Decroly. Centro de Interesse: alimentação. Assunto: o abacate. Revista do Ensino. Belo Horizonte, v. 4, no 33. p. 63-64, maio, 1929 b.

BARROS, M. G. Secção do Centro Pedagógico Decroly. Centro de Interesse: A necessidade de luctar contra a intemperies. Revista do Ensino. Belo Horizonte, v. 4, no 34. p. 58-60, jun., 1929 c.

BICCAS, M. S. O impresso como estratégia de formação Revista do Ensino de Minas Gerais (1925-1940). Belo Horizonte: Argumentum, 2008.

CARVALHO, C. H. Escola Nova, educação e democracia: o projeto Francisco Campos para a escola em Minas Gerais. Acta Scientiarum Education, Maringá, v. 34, n. 2, p. 187-198, jul./dez. 2012. https://doi.org/10.4025/actascieduc.v34i2.17421 
CHARTIER, R. A História Cultural: entre práticas e representações. Rio de Janeiro: Bertrand Brasil S.A., 2002.

CHARTIER, R. A “nova” História Cultural. In: GARNICA, A. V. M. (org.). Pesquisa em História da Educação Matemática no Brasil: sob o signo da pluralidade. São Paulo: Livraria da Física, 2016. p. 19-36.

CHERVEL, A. História das disciplinas escolares: reflexões sobre um campo de pesquisa. Teoria \& Educação, n. 2, p. 177-229, 1990.

DE CERTEAU, M. A Escrita da História. Rio de Janeiro: Forense-Universitária, 1982.

FERNANDES, J. C. B. A aritmética, os centros de interesse e o saber profissional do professor que ensina matemática, 1920-1940. 2020. 135f. Tese (Doutorado em Ciências). Universidade Federal de São Paulo. Guarulhos, SP, 2020. Disponível em: https://repositorio.ufsc.br/handle/123456789/221246. Acesso em: 15 fev. 2021.

FONSECA, S. S. Aproximações e distanciamentos sobre os saberes elementares geométricos no ensino primário entre Sergipe e São Paulo (1911-1930). 2015. 114f. Dissertação (Mestrado em Ensino de Ciências Naturais e Matemática). Universidade Federal de Sergipe, São Cristóvão, SE, 2015. Disponível em:

https://repositorio.ufsc.br/handle/123456789/133877. Acesso em: 15 fev. 2021.

FONTES, J. S. Classes de Aperfeiçoamento: ensaio da escola ativa no ensino primário em Sergipe (1932-1933). 2018. 145f. Dissertação (Mestrado em Ensino de Ciências Naturais e Matemática). Universidade Federal de Sergipe, São Cristóvão, SE, 2018. Disponível em: https://ri.ufs.br/bitstream/riufs/9495/2/JULIANA_SANTOS_FONTES.pdf. Acesso em: 15 fev. 2021.

HOFSTETTER, R.; SCHNEUWLY, B. (2017). Saberes: um tema central para as profissões do ensino e da formação. In: HOFSTETTER, R.; VALENTE, W. R. (org.). Saberes em (trans)formação: tema central da formação de professores. São Paulo: Livraria da Física, 2017. p. 113-172.

JULIA, D. A cultura escolar como objeto histórico. Revista Brasileira de História da Educação, v. 1, n. 1, p. 9-43, jan./jun. 2001. Disponível em: https://periodicos.uem.br/ojs/index.php/rbhe/article/view/38749 . Acesso em: 11 fev. 2021.

LUCA, T. R. Fontes Impressas: História dos, nos e por meio dos periódicos. In: PINSKY, C. B. (Org.). Fontes Históricas. São Paulo: Editora Contexto, 2008. p. 111-153.

MARQUES, C. L. A Voz da Pratica: Plano de Lição: Centro de Interesse: O porco. Revista do Ensino. Belo Horizonte, v. 5, nº 43. p. 55-67, mar., 1930.

MINAS GERAIS, Collecção das Leis e Decretos (1927). Belo Horizonte: Imprensa Official do Estado, v. 3, 1928.

OLIVEIRA, J. Secção do Centro Pedagógico Decroly - O Systema Decroly. Revista do Ensino. Belo Horizonte, v. 4, nº 26. p. 98-105, out., 1928a. 
OLIVEIRA, J. Secção do Centro Pedagógico Decroly: Um programa de escola infantil.

Revista do Ensino. Belo Horizonte, v. 4, nº 28. p. 52-55, dez., 1928 b.

RODRIGUES, E.; BICCAS, M. S. Imprensa pedagógica e o fazer historiográfico: o caso da Revista do Ensino (1929 - 1930). Acta Scientiarum Education, Maringá, v. 37, n. 2, p. 151163, abr./jun. 2015. https://doi.org/10.4025/actascieduc.v37i2.22666

SEIXAS, D. M. A Voz da Pratica: Plano de Lição - Centro de Interesse: o feijão. Revista do Ensino. Belo Horizonte, v. 5, nº 42. p. 55-56, fev., 1930.

SOUZA. A. F. Discursos sobre problemas aritméticos (São Paulo, 1890-1930). 2017. 135f. Dissertação (Mestrado em Ciências). Universidade Federal de São Paulo. Guarulhos, SP, 2017. Disponível em: https://repositorio.unifesp.br/handle/11600/50870. Acesso em: 15 fev. 2021.

VALDEMARIN, V. T. História dos métodos e materiais de ensino: a Escola Nova e seus modos de uso. São Paulo: Cortez Editor, 2010.

VALENTE, W. R. Aritmética e interdisciplinaridade: ecos da história da educação matemática. Educar em Revista, Curitiba, v. 35, n. 75, p. 305-318, mai./jun. 2019. https://doi.org/10.1590/0104-4060.66837

VALENTE, W. R.; PINHEIRO, N. V. L. A Matemática nos Livros Didáticos em Tempos de Pedagogia Científica. In: MENDES, I. A.; VALENTE, W. R. (Org.). A Matemática dos Manuais Escolares: Curso Primário, 1890-1970. São Paulo: Editora LF, 2017, p. 69-108.

VALENTE, W. R.; BERTINI, L. F.; MORAIS, R. S. Novos aportes teórico-metodológicos sobre os saberes profissionais na formação de professores que ensinam Matemática. Acta Scientiae, Canoas, v. 19, n. 2, p. 224-235, mar./abr. 2017. Disponível em: http://www.periodicos.ulbra.br/index.php/acta/article/view/2816/2299. Acesso em: $20 \mathrm{dez}$. 2020.

\section{NOTAS}

\section{AGRADECIMENTOS}

Não se aplica.

\section{FINANCIAMENTO}

O presente trabalho foi realizado com apoio do Conselho Nacional de Desenvolvimento Científico e Tecnológico (CNPq).

\section{CONTRIBUIÇÕES DE AUTORIA}

Resumo/Abstract/Resumen: Robert Rene Michel Junior e David Antonio da Costa Introdução: Robert Rene Michel Junior e David Antonio da Costa Referencial teórico: Robert Rene Michel Junior e David Antonio da Costa Análise de dados: Robert Rene Michel Junior e David Antonio da Costa Discussão dos resultados: Robert Rene Michel Junior e David Antonio da Costa Conclusão e considerações finais: Robert Rene Michel Junior e David Antonio da Costa Referências: Robert Rene Michel Junior e David Antonio da Costa 
Revisão do manuscrito: Hortenila Cabral Della Méa

Aprovação da versão final publicada: Robert Rene Michel Junior e David Antonio da Costa

\title{
CONFLITOS DE INTERESSE
}

Os autores declararam não haver nenhum conflito de interesse de ordem pessoal, comercial, acadêmico, político e financeiro referente a este manuscrito.

\section{DISPONIBILIDADE DE DADOS DE PESQUISA}

Os autores declaram disponibilizar os dados analisados para leitores interessados.

\section{CONSENTIMENTO DE USO DE IMAGEM}

Não se aplica.

\author{
APROVAÇÃO DE COMITÊ DE ÉTICA EM PESQUISA \\ Não se aplica.
}

\section{COMO CITAR - ABNT}

MICHEL JUNIOR, Robert Rene; COSTA, David Antonio da. A sistematização de saberes para ensinar aritmética na Revista do Ensino de Minas Gerais (1928-1930). REAMEC - Rede Amazônica de Educação em Ciências e Matemática. Cuiabá, v. 9, n. 3, e21088, set./dez., 2021. https://doi.org/10.26571/reamec.v9i3.13036

\section{COMO CITAR - APA}

Michel junior, R. R., \& Costa, D. A. (2021). A sistematização de saberes para ensinar aritmética na Revista do Ensino de Minas Gerais (1928-1930). REAMEC - Rede Amazônica de Educação em Ciências e Matemática, volume 9(3), e21088. https://doi.org/10.26571/reamec.v9i3.13036

\section{LICENÇA DE USO}

Licenciado sob a Licença Creative Commons Attribution-NonCommercial 4.0 International (CC BY-NC 4.0). Esta licença permite compartilhar, copiar, redistribuir o manuscrito em qualquer meio ou formato. Além disso, permite adaptar, remixar, transformar e construir sobre o material, desde que seja atribuído o devido crédito de autoria e publicação inicial neste periódico.

\section{DIREITOS AUTORAIS}

Os direitos autorais são mantidos pelos autores, os quais concedem à Revista REAMEC - Rede Amazônica de Educação em Ciências e Matemática - os direitos exclusivos de primeira publicação. Os autores não serão remunerados pela publicação de trabalhos neste periódico. Os autores têm autorização para assumir contratos adicionais separadamente, para distribuição não exclusiva da versão do trabalho publicada neste periódico (ex.: publicar em repositório institucional, em site pessoal, publicar uma tradução, ou como capítulo de livro), com reconhecimento de autoria e publicação inicial neste periódico. Os editores da Revista têm o direito de proceder a ajustes textuais e de adequação às normas da publicação.

\section{PUBLISHER}

Universidade Federal de Mato Grosso. Programa de Pós-graduação em Educação em Ciências e Matemática (PPGECEM) da Rede Amazônica de Educação em Ciências e Matemática (REAMEC). Publicação no Portal de Periódicos UFMT. As ideias expressadas neste artigo são de responsabilidade de seus autores, não representando, necessariamente, a opinião dos editores ou da referida universidade.

\section{EDITOR}

\section{Dailson Evangelista Costa (1D)}

\section{HISTÓRICO}

Submetido: 26 de setembro de 2021.

Aprovado: 25 de outubro de 2021.

Publicado: 06 de novembro de 2021. 